\title{
Aplikasi Jago (Baca Dan Tulis Pego) Dengan Voice Recognition Berbasis Android
}

\author{
Honainah1, Arifatul Hidayah2, Camelia Indah Nur Laily3 \\ ${ }_{1,2}$ Program Studi Informatika, Fakultas Teknik, Universitas Nurul Jadid, Probolinggo \\ ${ }^{1}$ naina.aja@gmail.com, ${ }^{2 h}$ hidayaharifatu1271@gmail.com, ${ }^{3}$ cameliaindah2207@gmail.com
}

\begin{abstract}
Pego merupakan huruf Arab yang dimodifikasi untuk menuliskan bahasa Jawa, bahasa Indonesia, dan Bahasa Sunda. Sekilas tulisan pego memang mirip dengan tulisan arab hijaiyah seperti biasanya. Tetapi masih ada tambahan huruf dan kaidah penulisannya yang membuat peserta didik kesulitan dalam menyesuaikan kosa kata dalam bentuk bahasa Indonesia atau bahasa selainnya. Sekolah MI Darul Ulum II merupakan salah satu sekolah yang memiliki materi "Arab pego" sebagai muatan lokal. Pembelajarannya berupa metode pengajaran menulis di papan dalam mengenal huruf pego dan cara penulisan pego. Sayangnya, metode ini membuat peserta didik mengalami kesulitan dalam mengenal huruf pego dan fungsi bacaan huruf pego untuk penulisan bahasa Indonesia atau bahasa Jawa. Karena itu dibutuhkan aplikasi yang dapat mempermudah peserta didik dalam proses belajar huruf pego. Tujuan penelitian ini untuk membuat aplikasi media pembelajaran dengan android dalam pembelajaran pego. Aplikasi ini dibuat menggunakan model pengembangan sistem waterfall. Aplikasi ini didesain dengan unfield modelling language (UML). Penelitian ini menghasilkan aplikasi pembelajaran jago (belajar menulis dan membaca pego) dengan voice recognition berbasis android menggunakan Adobe Flash Professional CS6. Aplikasi pembelajaran pego berbasis android ini dibangun dengan beracuan pada panduan baca tulis Arab-Melayu dan dengan suatu pengajaran menarik.
\end{abstract}

Keywords - Pego, Android, Adobe Flash Profesional CS6.

Abstrak - Pego is an Arabic script that is modified to write Javanese, Indonesian, and Sundanese languages. At first glance, Pego's writing is similar to Arabic hijaiyah writing as usual. But there are still additional letters and writing rules that make it difficult for students to adjust vocabulary in Indonesian or other languages. MI Darul Ulum II School is one of the schools that has "Arabic pego" material as local content. The learning is in the form of teaching writing on the board in recognizing the letters of pego and how to write pego. Unfortunately, this method makes it difficult for students to recognize pego letters and the function of reading pego letters for writing Indonesian or Javanese.Therefore we need an application that can help students in the process of learning the letter pego. This study aims to create an Android-based learning media application in Pego learning. The application in this study was developed using the waterfall system development model. This application is designed with unfield modeling language (UML). The result of this research is that a good learning application (learning to write and read pego) with android-based voice recognition has been built using Adobe Flash Professional CS6. This android-based Pego learning application was built with reference to Arabic-Malay reading and writing guidelines and with an interesting teaching.

Kata Kunci - Pego, Android, Adobe Flash Profesional CS6.

\section{PENDAHULUAN}

Pego merupakan huruf Arab yang dimodifi untuk menuliskan bahasa Jawa atau bahasa Sunda [1]. Pego berasal dari Jawa, yang berarti menyimpang. Sebab bahasa Jawa yang ditulis dalam huruf Arab dianggap sesuatu yang tidak lazim. Pada dasarnya huruf pego sama dengan huruf hijaiyah tapi tidak semua huruf hijaiyah digunakan dalam penulisan bahasa Indonesia atau bahasa Jawa dalam bentuk pego karena bacaan tulisannya yang sama. Dalam penulisan pego terdapat tambahan huruf dan kaidah-kaidah tertentu untuk penyesuaian bahasa agar mendapatkan hasil bacaan yang sama dengan hasil bacaan bahasa Indonesia atau bahasa Jawa. Seiring perkembangan zaman, pego tidak hanya menggunakan bahasa Jawa atau Sunda tetapi juga menggunakan bahasa Indonesia. Oleh karena itu, dalam penulisan pego dibutuhkan penyesuaian bahasa, seperti penggunaan harakat serta beberapa penambahan huruf yang tidak terdapat dalam huruf hijaiyah, seperti penambahan titik tiga di atas dan di bawah huruf. Selain tambahan huruf tersebut, dalam penulisan pego juga ada tambahan huruf vokal dan terdapat beberapa kaidah penulisan didasarkan pada huruf yang dimodifikasi. Dalam pembelajaran pego dibutuhan sebuah media pembelajaran atau aplikasi agar mempermudah peserta didik untuk memahami pego. Media pembelajaran merupakan bahan pembelajaran yang digunakan oleh peserta didik dalam mempermudah dalam belajar [2]. Bahan pembelajaran merupakan bahan khusus dalam suatu pelajaran yang disampaikan melalui berbagai macam media. Dalam proses pembelajaran diupayakan terciptanya komunikasi dua arah antara pengajar dengan siswa. Media pembelajaran merupakan salah satu faktor untuk meningkatkan minat belajar peserta didik, hal ini telah terbukti melalui beberapa penelitian 
diantaranya yang dilakukan oleh supriyono [3]. Dalam pendidikan non-formal, pelajaran tentang pego sangat tidak asing. Hal ini karena pego sudah digunakan oleh pondok pesantren untuk memaknai atau mengartikan kitab sejak zaman dahulu. Sekilas tulisan pego memang mirip dengan tulisan arab hijaiyah seperti biasanya. Tetapi masih banyak peserta didik yang belum mengerti dan memahami pego. Hal ini disebabkan karena siswa kurang berminat dalam belajar pego. Banyaknya peserta didik yang kurang berminat bisa disebabkan proses pembelajaran yang membuat bosan karena materi yang disampaikan kurang menarik.

Seperti halnya sekolah Madrasah Darul Ulum II, dalam pembelajaran pego (menurut ibu Chandra guru disekolah ini pego di sebut dengan protolan) masih menggunakan metode pengajaran menulis di papan dalam mengenal huruf pego dan cara penulisan pego. Sehingga peserta didik mengalami kesulitan dalam mengenal huruf pego dan fungsi bacaan huruf pego untuk penulisan bahasa Indonesia atau bahasa Jawa. Mereka juga kesulitan dalam mengenal huruf vokal pego serta kaidah-kaidah yang terdapat dalam pego. Hal dapat dilihat pada saat peserta didik diberi tugas menulis sebuah kalimat dalam bentuk bahasa Indonesia menjadi bentuk arab pego masih banyak terjadi kesalahan.

Dengan demikian, maka diperlukan media atau pembelajaran yang dapat membantu siswa belajar menulis dan membaca pego menggunakan Adobe Flash CS6 yang merupakan multimedia berbasis android. Penerapan aplikasi android banyak digunakan oleh beberapa penelitian karena dapat mempermudah penggunanya dan bisa diakses darimanapun dan kapanpun. Hal ini terbukti melalui hasil penelitian dari Muhammad Noor dan Risenna [4] dan Andhika Naufaliawan, Rizal Isnanto, dan Ike Pertiwi Windasari [5]. Aplikasi pembelajaran menggunakan Adobe Flash CS6 sangat menarik untuk dikembangkan. Salah satu keunggulan media pembelajaran menggunakan Flash adalah membuat objek sesuai dengan keinginan kita, baik gambar, suara, atau animasi gerakan serta dapat berjalan atau berdiri sendiri tanpa kita memiliki master program adobe flash [6]. Pengguaan Adobe Flash CS6 dapat disandingkan dengan pengguaan voice recognation untuk melengkapi aplikasi yang dibuat. Fungsi dari voice recognation yaitu mengenali seseorang melalui fitur suara yang ada [7]. Kombinasi pengguaan Android, Adobe Flash CS6 dan voice recognition akan menjadi solusi berupa media pembelajaran dalam meningkatkan minat belajar peserta didik sehingga tidak mudah bosan dalam mempelajari pego karena media pembelajaran tersebut dapat dijalankan pada Smartphone yang dapat diakses kapanpun dan darimanapun juga.

Mengacu pada hal tersebut maka identifikasi masalah yang terjadi dalam proses pembelajaran pego:

1. Guru masih menggunakan metode pengajaran menulis di papan dalam mengenal huruf pego dan cara penulisan pego

2. Peserta didik kesulitan dalam mengenal huruf vokal pego serta kaidah-kaidah yang terdapat dalam pego.

\subsection{Rumusan Masalah}

1. Bagaimana membuat aplikasi pembelajaran huruf pego menggunakan Adobe Flash Profesional CS6 berbasis android biar siswa lebih mudah paham pelajaran agar siswa tidak bosan dan lebih semangat dalam proses pembelajaran.

2. Bagaimana membuat aplikasi pembelajaran huruf pego menggunakan Adobe Flash Profesional CS6 berbasis android yang dapat mempermudah guru memberi materi pada siswa.

1.2 Tujuan Penelitian

1. Menghasilkan aplikasi pembelajaran huruf pego menggunakan Adobe Flash Profesional CS6 berbasis android yang dapat menambah minat peserta didik belajar pego.

2. Guru dan siswa mudah dalam belajar huruf pego.

1.3 Urgensi Penelitian

1. Sangat dibutuhkan apilkasi pego yang diintegrasikan dalam bentuk android untuk meningkatkan minat peserta didik sehingga tidak mudah bosan dalam mempelajari baca dan tulis huruf pego dan dapat diakses melalui smartphone kapanpun dan di manapun.

2. Aplikasi pego berbasis android dibuat yang interaktif dan menarik sebagai solusi sulitnya proses pembelajaran baca dan tulis huruf pego bagi peserta didik di seluruh sekolah yang memiliki mata pelajaran tersebut, sehingga lebih mudah dalam memahaminya.

\section{METODE PENELITIAN}

Metode penelitian yang digunakan dalam penelitian ini adalah pendekatan kualitatif dengan metode deskriptif. Metode penelitian yang digunakan adalah metode kualitatif. "Metodologi adalah proses, prinsip, dan prosedur yang kita gunakan untuk mendekati problem dan mencari jawaban" [8]. Tujuan metode ini untuk memberi deskipsi, gambaran atau lukisan secara sistematis, faktual dan akurat mengenai fakta, sifat juga keterkaitan fenomena yang diteliti. Penggunaan pendekatan berorientasi objek supaya metode analisis dan perancangan yang digunakan adalah UML (Unified Modeling Language). UML menjadi alat pendukung [9]. Berikut diagram alir tahapan penelitian yang dilakukan. 


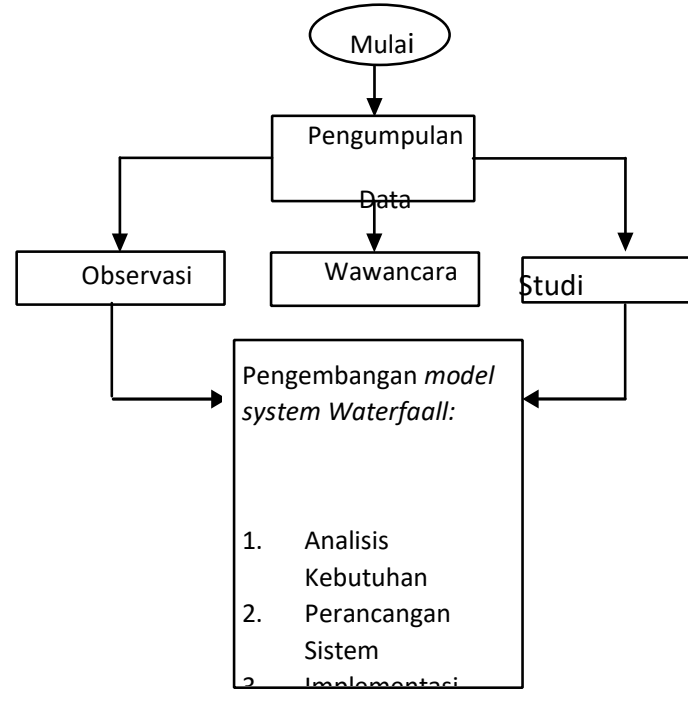

Aplikasi Jago (Baca danTulis Pego) Dengan Voice Recognation Berbasis Android

Gambar 1. Diagram Alur Proses Penelitian

Gambar 1 di atas dimulai dengan melakukan pengumpulan data melalui observasi dan wawancara dengan pihak lembaga. Selanjutnya melalui data-data yang dihasilkan melalui observasi dan wawancara dikelolah dengan ditambahi studi pustaka, langkah selanjutnya yakni memilih model pengembangan sistem yang sesuai dengan permasalahan yang dihadapi yakni model pengembangan waterfall, model ini sangat efektif digunakan karena dilakukan secara berurutan artinya proses saat ini dilakukan jika proses sebelumnya selesai.

Menurut Pressman dan Sommerville (dalam Muharto dan Ambarita 2016:106), [10] ada beberapa tahapan dalam pengembangan sistem waterfall yakni analisis kebutuhan, perancangan sistem, implementasi dengan codeigniter, pengujian sistem memakai teknik blackbox dan pengujian eksternal pada pihak guru dan peserta didik untuk mengetahui aplikasi telah sesuai dengan harapan, selanjutnya maintenance. terakhir penerapan aplikasi terhadap guru dan peserta didik.

\section{HASIL DAN PEMBAHASAN}

\subsection{Hasil Analisis}

Berdasarkan hasil reservasi terhadap media pembelajaran pego yang menggunakan media di atas, dirasa kurang menarik untuk terus digunakan dalam pembelajaran. Maka dalam penelitian ini diberikan rekomendasi aplikasi media pembelajaran pego berbasis android agar lebih interaktif dan menarik dalam kegiatan belajar dan mengajar baik di dalam maupun di luar kelas. Analisis kebutuhan perangkat digunakan untuk mengidentifikasi terhadap kebutuhan program yang baru. Kebutuhan perangkat meliputi analisis kebutuhan software, dan analisis kebutuhan hardware sebagai rekomendasi pembuatan program baru. Aplikasi ini membutuhkan desain menarik, interaktif dan multimedia yang dapat mendukung pembelajaran pego siswa dapat dengan mudah mempelajari dan memahaminya.

Aplikasi ini memiliki empat menu pada menu utama , menu, kuis, profil, dankeluar. Menu akan menampilkan 3 materi yaitu: pengertian pego, huruf pego dan kaidah pego. Kuis akan menampilkan soalsoal latihan siswa saat mempelajari pego. Kuis ini melatih siswa untuk mengetahui seberapa jauh materi yang sudah diserap. Selain di atas, terdapat menu profil yang berisi tentang profil penulis. Pada keluar pilihan untuk keluar dari aplikasi. Pengujian pada penelitian ini menggunakan pengujian internal kepada 3 dosen ahli dan guru muatan lokal serta pengujian eksternal kepada 10 orang responden. Hasil pengujian kepada responden dan dosen ahli menyatakan bahwa aplikasi ini dapat diterima dan layak digunakan karena telah memenuhi kebutuhan user.

3.2 Hasil Perancangan Sistem pengodean dalam pembuatan aplikasi

Adapun gambar dan keterangan gambar dari hasil pembuatan aplikasi jago (baca dan tulis pego) multimedia pintar caraka untuk pembelajaran aksara Jawa dalam hal ini berbasis android ialah sebagai berikut:

\section{Use Case Diagram}

Pada use case diagram digambarkan segala aktifitas yang dilakukan sistem. Pada use case diagram pertama ialah saat user menjalankan aplikasi maka akan memasuki halaman utama (tampilan awal) terdapat 4 pilihan yaitu menu, profil, quiz, dam keluar. 


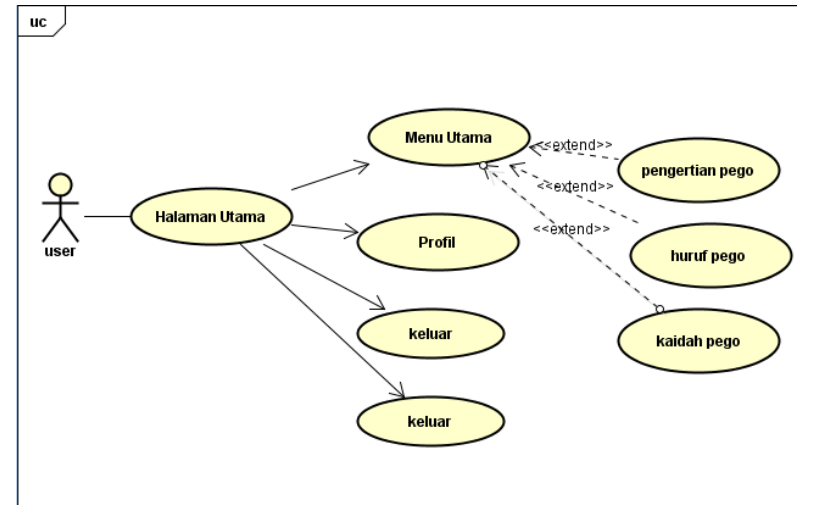

Gambar 2. Use Case Diagram Aplikasi Pego

\section{Activity Diagram}

Pada activity diagram ialah memberi gambaran aliran aktivitas pada sistem yang dirancang, bagaimana masing-masing alur berawal, alur yang mungkin terjadi, dan akhir dari aktivitas. Activity diagram pada aplikasi media pembelajaran pego ialah user membuka aplikasi pego maka akan muncul loading dan akan menampilkan halaman utama dari aplikasi ini, di mana pada halaman ini terdapat tiga pilihan yaitu menu, profil dan quiz.

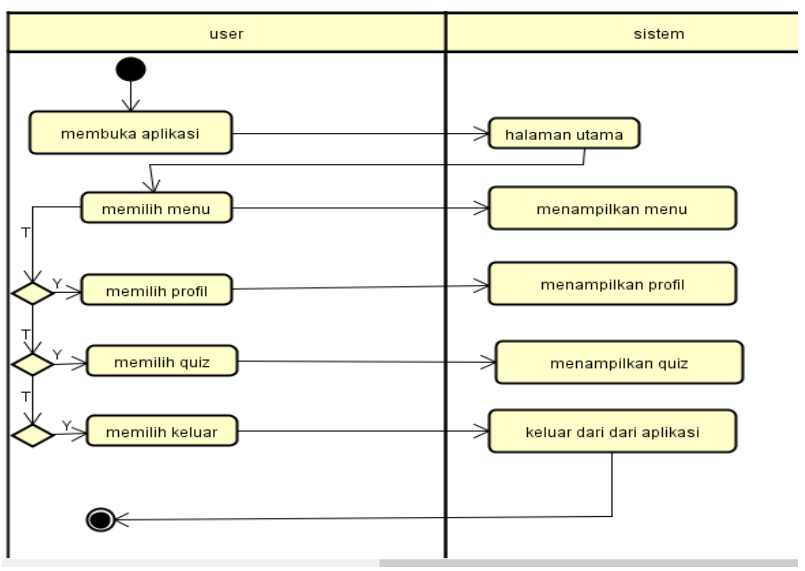

Gambar 3. Activity Diagram Pego.

\section{Sequence Diagram}

Sequence Diagram merupakan diagram yang menggambarkan hubungan antar obyek dan mengindikasi komunikasi diantara objek tersebut.

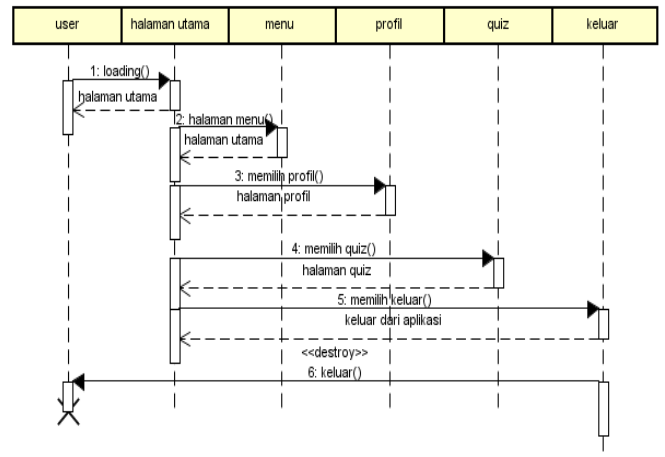

Gambar 4. Sequence Diagram Aplikasi Pego

\subsection{Hasil Implementation}

Implementation adalah tahapan pengkodean setelah tahapan requirement dan design dari analis sistem terdahulu. Implementasi merupakan tahapan aplikasi siap dioperasikan pada keadaan yang sebenarnya sehingga dapat diketahui apakah program yang kita buat benar-benar dapat menghasilkan sebuah aplikasi yang sesuai dengan tujuan yang diinginkan.

1. Tampilan Halaman Utama (tampilan awal)

Pada tampilan ini user akan ditampilkan dengan empat tombol yaitu menu, profil, quiz dan keluar seperti yang ditunjukkan pada gambar 5 .

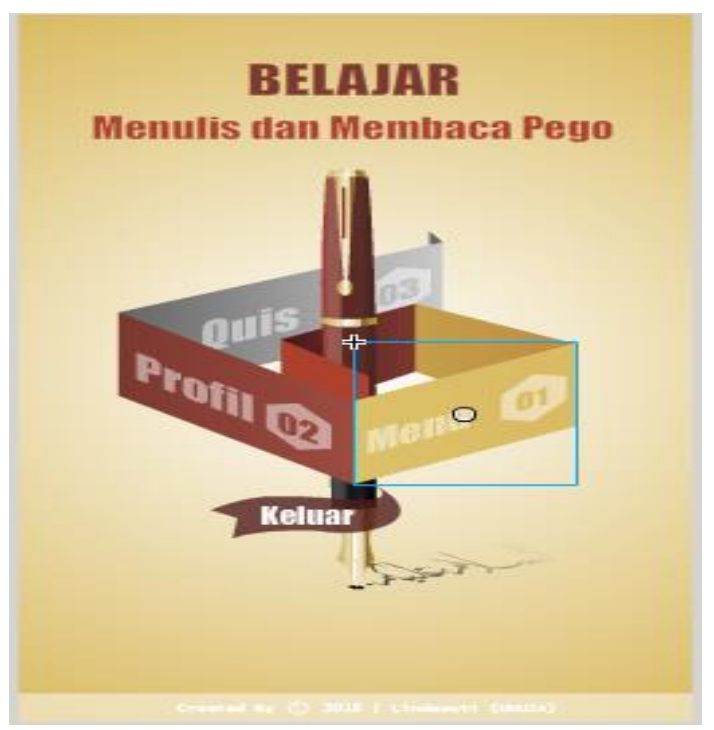

Gambar 5. Tampilan Halaman Utama

\section{Tampilan Menu}

Pada menu, user dihadapakan dengan empat icon yaitu definisi (pengertian) pego, huruf pego dan kaidah pego yang ditunjukkan pada gambar 6 . 


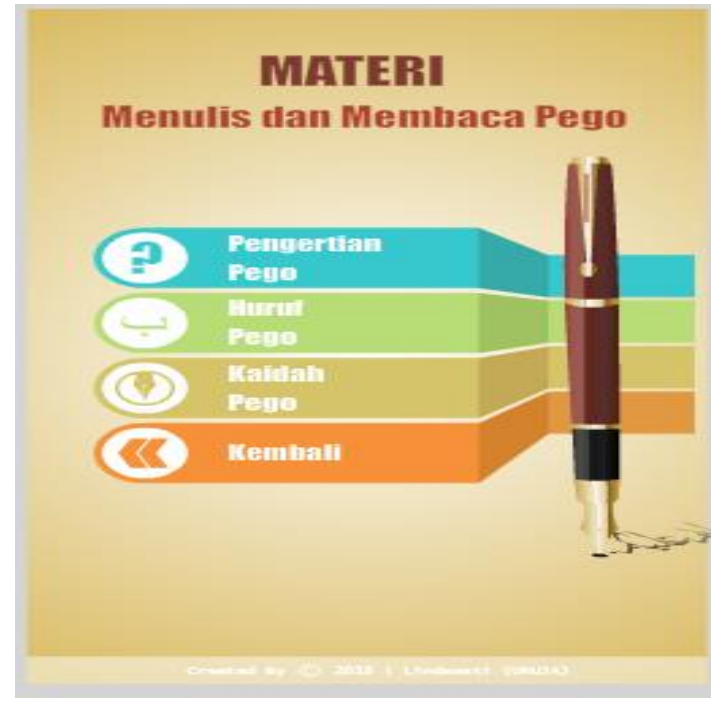

Gambar 6. Tampilan Menu

Dalam menu ada empat pilihan yaitu definisi, huruf, kaidah dan kembali. Salah satu contoh tampilan menu pada huruf akan ditunjukkan pada 7

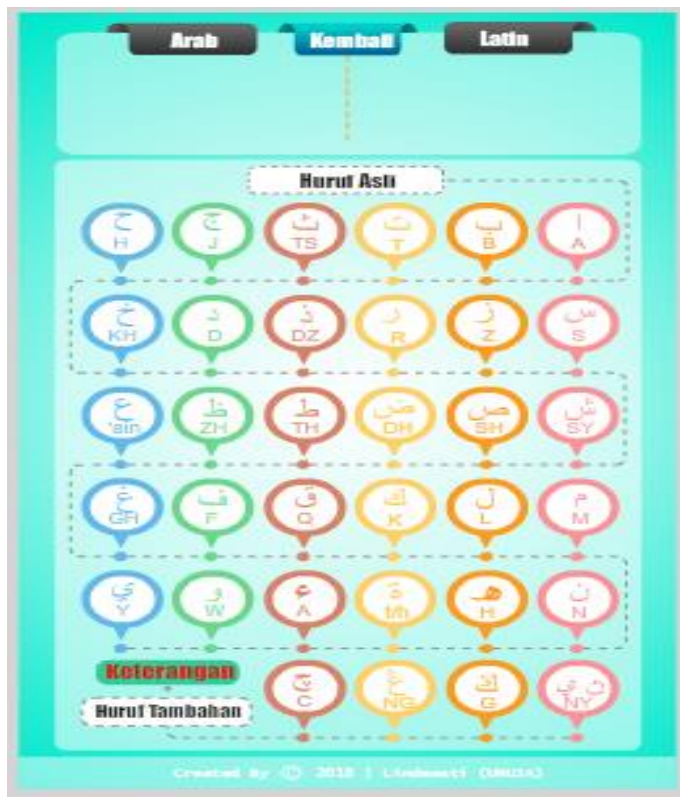

Gambar 7. Tampilan Menu (Huruf Pego).

\section{Tampilan Quiz}

Pada tampilan quiz user akan dihadapakan dengan tampilan profil seperti yang ditujukan pada gambar 8 .

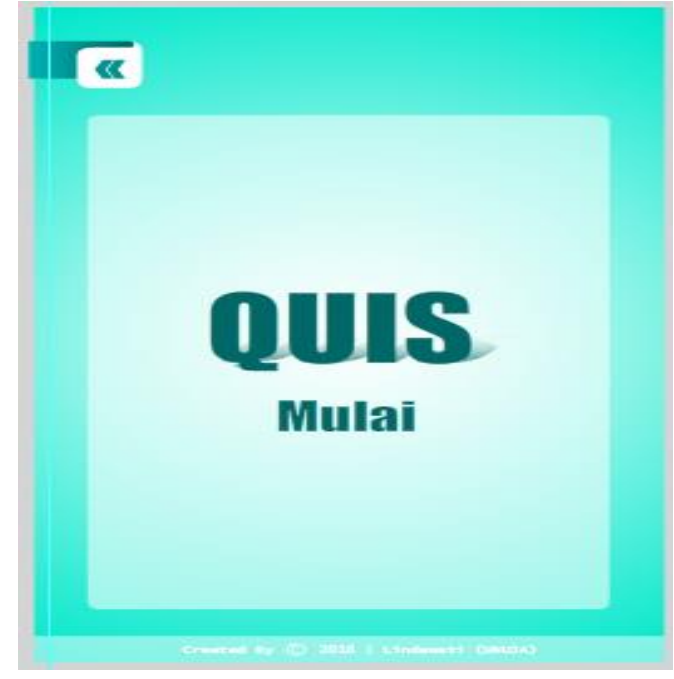

Gambar 8. Tampilan Quis

Contoh salah satu tampilan quiz di tunjukkan pada gambar 9 .

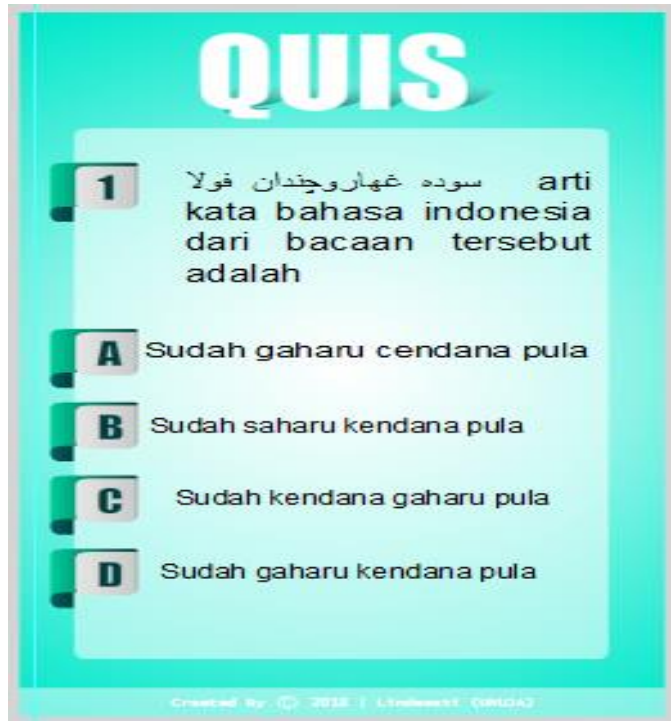

Gambar 9. Salah Satu Tampilan Quis

\subsection{Hasil Testing}

Untuk melihat kesesuain aplikasi dengan kebutuhan user maka diperlukan adanya hasil uji yang berupa hasil uji secara internal (black box) dan pengujian eksternal.

a. Pengujian black box

Pengujian ini digunakan menguji aplikasi pembelajaran pego yang bertujuan mengetahui seberapa mudah aplikasi ini digunakan oleh user. 
Tabel 1. Hasil Pengujian black box

\begin{tabular}{|c|c|c|c|}
\hline \multirow[b]{2}{*}{ Masukan/Kondisi } & \multirow[b]{2}{*}{ Keluaran/Respon } & \multicolumn{2}{|c|}{ Hasil $\mathrm{Uji}$} \\
\hline & & Diterima & $\begin{array}{l}\text { Tidak } \\
\text { diterima }\end{array}$ \\
\hline $\begin{array}{l}\text { Pengguna masuk untuk } \\
\text { yang pertama kali }\end{array}$ & $\begin{array}{l}\text { Program menampilkan } \\
\text { halaman utama aplikasi }\end{array}$ & $\checkmark$ & \\
\hline $\begin{array}{l}\text { Pengguna memilih masuk } \\
\text { pada menu }\end{array}$ & $\begin{array}{l}\text { Program akan } \\
\text { menampilkan } 4 \text { menu di } \\
\text { dalam menu }\end{array}$ & ل & \\
\hline $\begin{array}{l}\text { Pengguna memilih masuk } \\
\text { pada salah satu } \\
\text { tombol di menu }\end{array}$ & $\begin{array}{l}\text { Program akan } \\
\text { menampilkan halaman } \\
\text { tombol yang dipilih }\end{array}$ & $\sqrt{ }$ & \\
\hline $\begin{array}{l}\text { Pengguna memilih masuk } \\
\text { pada quiz }\end{array}$ & \begin{tabular}{|lr} 
Program & akan \\
menampilkan & macam \\
quiz &
\end{tabular} & $\sqrt{ }$ & \\
\hline $\begin{array}{l}\text { Dengguna memilih masuk } \\
\text { pada profil }\end{array}$ & $\begin{array}{l}\text { Program akan } \\
\text { menampilkan profil }\end{array}$ & $\sqrt{ }$ & \\
\hline Pengguna memilih keluar & Program akan keluar. & $\sqrt{ }$ & \\
\hline
\end{tabular}

b. Pengujian External

Testing External pada aplikasi ini adalah memberikan beberapa pertanyaan kepada peserta didik menggunakan angket, agar memperoleh penilaian dari user. Berikut adalah adalah hasil angket penilaian dari peserta didik yang di beri angket.

Tabel 2. Hasil Pengujian eksternal

\begin{tabular}{|c|c|c|c|c|c|}
\hline \multirow[b]{2}{*}{ No } & \multirow[b]{2}{*}{ Kriteria } & \multicolumn{4}{|c|}{ Hasil } \\
\hline & & SS & $\mathrm{S}$ & TS & STS \\
\hline 1. & Apaksah aplikasi ini berjalan dengan baik? & $\sqrt{ }$ & & & \\
\hline 2. & $\begin{array}{l}\text { Apakah pengguna mengalami kesulitan dalam } \\
\text { menggunakanxa? }\end{array}$ & $\sqrt{ }$ & & & \\
\hline 3. & $\begin{array}{l}\text { Apakah pengguna dapat dengan mudah } \\
\text { memahami pembelajaran pego? }\end{array}$ & & $\sqrt{ }$ & & \\
\hline 4. & $\begin{array}{l}\text { Apakah anda senang jika media pembelajaran } \\
\text { pego menggunakan aplikasi } \\
\text { berbasis android? }\end{array}$ & $\sqrt{ }$ & & & \\
\hline 5. & $\begin{array}{l}\text { Apa ada fitur yang eror pada aplikasi ketika } \\
\text { dijalankan? }\end{array}$ & & & $\sqrt{ }$ & \\
\hline 6. & $\begin{array}{l}\text { Apakah aplikasi ini bisa digunakan oleh semua } \\
\text { kalangan peserta didik? }\end{array}$ & $\sqrt{ }$ & & & \\
\hline 7. & Adakah materi yang kurang dalam aplikasi ini? & & $\sqrt{ }$ & & \\
\hline 8. & Apakah fitur animasi yang digunakan menarik? & $\sqrt{ }$ & & & \\
\hline 9. & Adakah pelafalan suara ielas dan dimengerti? & & $\sqrt{ }$ & & \\
\hline 10. & $\begin{array}{l}\text { Adakah salah satu sontoh yang salah dengan } \\
\text { pelafalannya? }\end{array}$ & & $\sqrt{ }$ & & \\
\hline
\end{tabular}

\section{KESIMPULAN}

Berdasarkan hasil uji pada bab sebelumnya ditarik kesimpulan telah dihasilkan aplikasi pembelajaran huruf pego menggunakan adobe flash professional CS6 berbasis android yang dapat memberikan manfaat dan memudahkan peserta didik dalam proses pembelajaran pego. terbukti dari hasil uji yang telah dilakukan.

\section{DAFTAR PUSTAKA}

[1] Mujahid, Muhammad. (2016) "Panduan Baca Tulis Arab-Melayu”. Makasar: Keagamaan Padang: 2016: 1-20.

[2] Yaumi, Muhammad. 2013. "Prinsip-Prinsip Desain Pembelajaran". Jakarta: Kencana Prenada

[3] Supriyono. (2018). "Pentingnya Media Pembelajaran Untuk Meningkatkan Minat Belajar Siswa SD”. Surabaya. Universitas Negeri Surabaya.

[4] Muhammad Noor dan Risenna. (2016). "Aplikasi Pintar Membaca Huruf Hijaiyah Pada Anak Usia Dini Berbasis Android". Politeknik Negri Tanah Laut.

[5] Andhika Naufaliawan, Rizal Isnanto, dan Ike Pertiwi Windasari. (2015). "Pengembangan Permainan Angka dan Huruf Hijaiyah Berbasis Android". Semarang: Universitas Diponegoro

[6] Madcoms. 2011. "Kupas Tuntas Adobe Flash Profesional CS6". Yogyakarta: Andi.

[7] Amin Mutohar. (2007). "Voice Recognition". Jurusan Teknik Fisika. Institut Teknologi Bandung. Bandung: 2007: 2-3.

[8] Mulyana, Deddy. (2008). Metodologi Penelitian Kualitatif. Bandung: PT Remaja Rosda Karya.

[9] M. Petre, "UML in practice," in Proceedings International Conference on Software Engineering, 2013

[10] Muharto, dan Ambarita Arisandy, 2016, Metode Penelitian Sistem Informasi, Yogyakarta: Deepublish 